Cahiers $d u$ MONDE RUSSE

\section{Cahiers du monde russe}

Russie - Empire russe - Union soviétique et États indépendants

$49 / 4 \mid 2008$

Destins individuels et terreur. Jeunesse dans la société post-stalinienne

\title{
Le souffle lointain de la révolution et la terreur du quotidien
}

Le bolchevik Emel'jan Jaroslavskij dans les années 1930

\section{Sandra Dahlke}

\section{(2) OpenEdition}

\section{Journals}

Édition électronique

URL : https://journals.openedition.org/monderusse/9496

DOI : 10.4000/monderusse. 9496

ISSN : $1777-5388$

Éditeur

Éditions de l'EHESS

Édition imprimée

Date de publication : 28 décembre 2008

Pagination : 581-604

ISBN : 978-2-7132-2197-2

ISSN : $1252-6576$

Référence électronique

Sandra Dahlke, "Le souffle lointain de la révolution et la terreur du quotidien », Cahiers du monde russe [En ligne], 49/4 | 2008, mis en ligne le 01 janvier 2008, consulté le 03 septembre 2022. URL http://journals.openedition.org/monderusse/9496; DOI : https://doi.org/10.4000/monderusse.9496 


\section{LE SOUFFLE LOINTAIN DE LA RÉVOLUTION ET LA TERREUR DU QUOTIDIEN}

\section{Le bolchevik Emel'jan Jaroslavskij dans les années 1930*}

En hiver 1936-1937, Emel' jan Jaroslavskij', dirigeant bolchevik de 58 ans, prend quelques semaines de repos à Barviša près de Moscou, dans un établissement réservé à l'élite de l'État soviétique et aux fonctionnaires haut placés du parti. Angoissé par sa faible santé physique et morale, paralysé par le marasme du lieu et usé par son travail, Jaroslavskij confie à son journal son désir passionné de rejoindre le front de la guerre civile d'Espagne et de participer de toutes ses forces au combat de l'armée républicaine ${ }^{2}$. Il n'est alors pas le seul à nourrir ce rêve. Son camarade Nikolaj Podvojskij, 56 ans, qui se repose aussi à Barviša, enflammé par l'idée de partir pour l'Espagne, en est à grand-peine dissuadé par Jaroslavskij qui lui fait valoir qu'il est trop âgé et trop malade pour se lancer dans pareille aventure ${ }^{3}$.

Le rêve de ces deux vieux bolcheviks - de toute évidence bien éloigné des réalités de leur situation - renvoie en fait à l'image d'eux-mêmes que les dirigeants bolcheviks de cette génération faisaient leur. La plupart d'entre eux se considéraient comme des « révolutionnaires professionnels », désignation identitaire qui figure dans nombre de « renseignements personnels » des formulaires standardisés que les membres du parti devaient remplir à l'adresse de différentes instances du parti. Dans

\footnotetext{
* Cet article a bénéficié du soutien du DAAD (Deutscher Akademischer Austauschdienst), en collaboration avec la MSH. La bourse qui m'a été attribuée m'a permis d'effectuer un séjour de recherche à l'EHESS/CERCEC. Je remercie les membres du CERCEC pour l'assistance qu'ils m'ont prêtée en relisant mon article.
}

1. Emel’jan Jaroslavskij (1878-1943), né Minej Izrailovič Gubel'man, commence à utiliser le prénom Emel'jan à partir de l'hiver 1903-1904, très probablement en référence au fameux rebelle paysan du XVIII ${ }^{\mathrm{e}}$ siècle, Emel'jan Pugačev. Le pseudonyme Jaroslavskij date de 1906, après les grèves qu'il organisa à Iaroslavl’ en automne 1905.

2. Journal, 25 décembre 1936. Archives familiales.

3. Journal, $1^{\mathrm{er}}$ janvier 1937. Archives familiales. 
son discours au XVII Congrès du parti en janvier 1934, Lazar Kaganovič réitère cette image héroïque du bolchevik en désignant le parti comme «l'armée des combattants révolutionnaires ».

Dans les années 1930, cette perception de soi était mise à mal pour deux raisons qui, bien que contradictoires, sont corrélées. En effet, l'ardeur révolutionnaire dont témoignent Jaroslavskij et Podvojskij était difficilement conciliable avec la routine et les exigences du gouvernement et de l'administration au quotidien d'un parti au pouvoir. Ensuite et surtout, en monopolisant la notion de révolutionnaire, Stalin et son plus proche entourage ont réussi à soumettre leurs camarades dirigeants à un régime disciplinaire aboutissant précisément à détruire toute routine de l'exercice journalier du pouvoir et toute certitude identitaire. Ce n'est donc pas un hasard si Kaganovič évoque l'esprit révolutionnaire et combattant précisément au cours du XVII ${ }^{e}$ Congrès, alors que beaucoup ont déjà nourri l'espoir d'une normalisation proche, l'espoir que ce congrès marque la fin des graves crises sociales et économiques déclenchées par la politique violente, considérée comme révolutionnaire, de la réquisition du blé et de la collectivisation forcée, et signifie l'arrêt des luttes incessantes pour le pouvoir à l'intérieur du parti .

Notre contribution, partie d'un travail biographique plus large sur le dirigeant bolchevik Emel'jan Jaroslavskij ${ }^{5}$, s'organise autour de deux axes problématiques. D'une part, elle cherche, à partir de cet exemple, à comprendre l'idée que se faisaient les bolcheviks de cette génération de leur qualité de révolutionnaire et quelles stratégies ils appliquèrent pour en conserver l'esprit dans les années 1930. D'autre part, elle se propose d'explorer comment ce concept du révolutionnaire fut employé et quelle en fut l'incidence dans l'interaction entre dirigeants bolcheviks en tant qu'instrument de discipline et d'autodiscipline. Tout en gardant pour trame ces deux problématiques, nous formulons l'hypothèse que c'est justement par l'instrumentalisation de la notion de révolutionnaire que Stalin réussit à imposer à ses camarades son pouvoir absolu.

L'analyse s'appuie sur deux types de sources : la correspondance personnelle de Jaroslavskij et ses journaux intimes. Jaroslavskij est un des rares bolcheviks de haut rang qui nous ait laissé des journaux personnels et une vaste correspondance privée, surtout avec sa femme, Klavdija Kirsanova, une bolchevik qui, dans les années 1920-1930, tint plusieurs hauts postes au sein du Komintern ${ }^{6}$. Nous avons pu étudier les journaux qui couvrent la période du 1er janvier 1934 au 2 mars 19377.

4. Oleg Hlevnjuk, Politbjuro : Mehanizmy političeskoj vlasti v 1930-e gody [Le politburo : les mécanismes du pouvoir politique dans les années 1930], M. : Rosspen, 1996, p. 99-103.

5. Sandra Dahlke, Emel'jan Jaroslavskij (1878-1943): Individuum und Herrschaft im Stalinismus, thèse de doctorat, université de Hambourg, 2005.

6. Cf. Julia Köstenberger, « Klavdija Kirsanova: Rektorin der Internationalen Leninschule in Moskau », Jahrbuch für Forschungen zur Geschichte der Arbeiterbewegung, 1, 2007, p. 78.

7. Malheureusement, le journal ne contient aucune note sur le déroulement du tristement célèbre plenum du CC en février-mars 1937, au cours duquel Rykov, Buharin et le dirigeant du NKVD Jagoda furent accusés. On peut supposer que Jaroslavskij a abandonné son journal lors des premiers jours du plenum. Pourtant quelques indications laissent penser qu'il a pris des notes avant 1934 et a continué à en prendre après février-mars 1937. Il est donc également possible qu'il y ait eu d'autres journaux, perdus ou bien détruits par mesure de précaution. 
Il s'agit là d'une source exceptionnelle pour appréhender les perceptions subjectives des contemporains et surtout leur manière de participer et de s'intégrer au régime stalinien ${ }^{8}$.

\section{Une biographie contrastée}

Jaroslavskij naît en 1878 à Čita sous le nom de Minej Izrailevič Gubel'man, dans une famille juive exilée en Sibérie. Devenu membre du parti social-démocrate vers 1900, il participe aux révolutions de 1905 et de 1917. Incarcéré plusieurs fois par les autorités tsaristes, il vit en exil à Iakoutsk de 1913 à 1917.

Dans les années 1920 et 1930, sa carrière est intimement liée à celle de Stalin. À cette époque, Jaroslavskij est un personnage politique très influent. Dans la hiérarchie du pouvoir, il vient immédiatement après les membres et candidats du Bureau politique. Il occupe des postes très importants dans les organes de contrôle suprêmes du parti. Dans ce cadre, il est, aux côtés de Stalin, l'un des principaux organisateurs de la lutte contre l'opposition intérieure et des « purges » continuelles au sein du parti.

Ses fonctions de contrôle sont alors étroitement liées à son engagement en tant qu'historien du bolchevisme. À partir de 1924 il contribue fortement à la construction du léninisme comme instrument de contrôle idéologique et, dans les années 1930, il est l'un des principaux promoteurs du culte de Stalin. Jaroslavskij prend, sous le contrôle de Stalin, une part déterminante à la rédaction de l'ouvrage idéologique majeur du stalinisme, son Histoire du parti communiste de l'URSS (parti bolchevik $)^{9}$, tristement célèbre ${ }^{10}$. Bien qu'il n'ait pas participé directement à l'organisation et à l'implantation de la Terreur, il contribue fortement à la préparer idéologiquement dans ses manuels d'histoire du parti comme dans les médias. Il va légitimer et populariser les répressions jusqu'à prôner l'élimination physique de ses anciens camarades.

8. Sur le débat au sujet de la valeur des journaux personnels de la période stalinienne comme source historique, voir Jochen Hellbeck, «Working, struggling, becoming : Stalin-Era Autobiographical Texts », The Russian Review, 60 (3), 2001, p. 340-359 ; Id., Revolution on my Mind : Writing a Diary under Stalin, Cambridge, MA : Harvard University Press, 2006 ; Véronique Garros, «L'État en proie au singulier. Journaux personnels et discours autoritaire dans les années 1930 », Le Mouvement social, 196 (3), 2001, p. 137-154.

9. Emel’jan Jaroslavkskij, Istorija VKP (b), Kratkij kurs, pod red. kommissii CK VKP(b), odobren CK VKP(b) [Histoire du Parti Communiste de 1'Union Soviétique (bolcheviks). Manuel abrégé, ss la réd. d'une commission du CC PCUS, approuvée par le CC PCUS], M., 1938. Ce manuel abrégé parut d'abord, chapitre par chapitre, dans la Pravda à partir du 9 septembre 1938 avant d'être publié à Moscou à plusieurs millions d'exemplaires. Jaroslavskij, Vil'gel'm Knorin et Petr Pospelov constituaient la commission en charge de rédiger cette histoire officielle sous le contrôle de Stalin. En 1956, dans le cadre de la « déstalinisation », sous Hruščev, cette histoire du parti fut réécrite.

10. Sandra Dahlke, «Emel’jan Jaroslavskij. Acteur dans le monde des historiens », Communisme. Revue d'Histoire, de Sociologie et de Science politique, 70/71, 2002, p. 213-245. 
Jusqu'à son décès, en 1943, il est resté un partisan loyal de Stalin — loyauté qui, au demeurant, n'empêche pas sa disgrâce au début des années 1930. En 1931, il est publiquement humilié par Stalin, ce qui lui vaut d'être mis à l'écart du cercle dirigeant. Dans sa fameuse « Lettre aux éditeurs du journal Proletarskaja revoljucija »11 du 28 octobre 1931, Stalin l'accuse d'avoir commis de graves erreurs dans les manuels d'histoire du parti et, implicitement, d'un « libéralisme pourri » ${ }^{12}$. Bien que les «erreurs» ne soient pas précisées, la lettre déclenche une campagne contre Jaroslavskij. Sous la pression, Jaroslavskij capitule en décembre 1931 : dans un article de repentance que publie la Pravda ${ }^{13}$ et sans bien sûr évoquer le nom de Stalin, il admet, entre autres «fautes », celles qui lui ont été imputées lors de la campagne, ainsi que son «erreur d'interprétation» des rapports modérés que «quelques bolcheviks » entretenaient avec le Gouvernement provisoire ${ }^{14}$. Après cet incident, sa position est instable. Mais ce n'est qu'à partir de 1936 que sa situation devient vraiment critique. Cette année-là, son remplaçant à la direction de la Société chargée de mener la propagande antireligieuse en Union soviétique (la ligue des sans-dieux militants), Lukačevskij, est incarcéré, puis exécuté un an plus tard. Son exécution visait probablement à menacer et intimider son supérieur, Jaroslavskij. Selon le témoignage de Nikita Hruščev, à l'époque chef de l'organisation du parti à Moscou, Jaroslavskij a échappé de justesse à une machination ourdie contre lui par Stalin et Malenkov lors des élections au Comité du parti moscovite en 193715. La même année, sa famille est directement atteinte par les répressions. Son gendre, le diplomate Marsel’ Rozenberg, est arrêté et exécuté en 1938. En novembre 1937, à l'initiative personnelle de Stalin, sa femme est accusée en tant qu'ennemie du peuple ${ }^{16}$. Exclue du parti, puis destituée de tous ses postes, elle a finalement survécu.

\section{Proletarskaja revoljucija, 6, 1931.}

12. Josif V. Stalin, «O nekotoryh voprosah istorii bol`ševizma » [De l'histoire du bolchévisme], Sočinenija [CEuvres complètes], vol. 13, M., 1951, p. 84-102, ici p. 101-102; L.G. Babičenko, «Pis'mo Stalina v "Proletarskuju Revoljuciju” i ego posledstvija » [La lettre de Stalin à la revue "Proleterskaja Revoljucija" et ses conséquences], Voprosy istorii KPSS, 6, 1990, p. 94-108.

13. Pravda, 10 décembre 1931 ; Bol``̌švik, 21, 1931,p. 84-86.

14. Les « quelques bolcheviks » sont Stalin et Kamenev qui, avant l'arivée de Lenin à SaintPétersbourg en avril 1917, avaient plaidé en faveur d'une collaboration avec le Gouvernement provisoire, une position vivement critiquée par Lenin. Un proche collaborateur de Jaroslavskij, David Kin, avait mentionné cette « erreur » de Stalin dans un manuel d'histoire du Parti rédigé par Jaroslavskij et publié en 1929.

15. Nikita S. Hruščev, Vremja, ljudi, vlast', vol. 1, M. : Moskovskie novosti, 1999, p. 126-129 (trad. française : Nikita Sergeïevitch Khrouchtchev, Souvenirs, P. : Robert Laffont, 1971).

16. Georgi Dimitroff, Tagebücher, 1933-1943, Berlin : Aufbau, 2000, p. 165, 167. Après les instructions de Stalin à Dimitrov, Kirsanova fut interrogée sur ses relations avec Marcel Rozenberg lors d'une réunion du parti à l'École internationale Lenin dont elle était la directrice. L'interrogatoire eut lieu en présence du représentant du Komintern au CC, Manuilskij, et elle fut accusée d'avoir entretenu des contacts politiques et sexuels avec des « ennemis du peuple». Licenciée de tous ses postes, elle fut exclue du parti. RGASPI (Rossijskij gosudarstvennyj arhiv social'no-političeskoj istorii - Archives d'État de Russie d'histoire politique et sociale), f. 531 , op. 2 , d. $45,1.48-161$. 


\section{L'appropriation d'une identité révolutionnaire}

Au regard de cette vie pleine de graves ruptures et de contradictions, une question demeure : pourquoi Jaroslavskij, comme beaucoup d'autres bolcheviks, continua-til à suivre Stalin, même à l'époque des purges lorsque sa famille et lui-même furent menacés ? Selon notre hypothèse, c'est à travers l'idée que les bolcheviks comme Jaroslavskij - intellectuel autodidacte sans racines prolétariennes - se faisaient de leur propre qualité de révolutionnaire, et à la faveur de leur crainte viscérale d'être aliéné de ce qu'ils nomment « le peuple » et plus tard « la masse ouvrière », que Stalin put les mettre au pas.

Comment et à partir de quelles sources Jaroslavskij a-t-il élaboré son image du révolutionnaire et s'est-il reconnu comme tel ? Il convient de rappeler ici l'œuvre classique de Leopold Haimson sur la social-démocratie russe au XIXe et au début du $\mathrm{XX}^{\mathrm{e}}$ siècle qui a attiré notre attention sur les catégories de spontanéité et d'émotion opposées à celles de conscience, voire de rationalité. L'auteur montre que l'on retrouve cette dichotomie non seulement dans l'analyse que les membres des différentes fractions du parti social-démocrate auraient faite de l'identité de la classe ouvrière mais également de leur propre expérience de vie. Haimson attribue cette double orientation d'auto-analyse à leur lecture de la philosophie matérialiste, de l'œuvre de Marx surtout, et à un romantisme populiste subjacent. Les sociauxdémocrates, comme les représentants de l'intelligentsia radicale, auraient été motivés par deux désirs dichotomiques : d'abord se situer dans la société russe en usant de modèles rationnels, considérés comme scientifiques, puis surmonter leur isolement par rapport à la population russe, parler au nom du « peuple opprimé » ${ }^{17}$.

L'analyse de Haimson est tout à fait pertinente ici. Le jeune Minej Gubel'man a passé les vingt premières années de sa vie dans sa ville natale de Čita qui est alors un centre d'activités commerciales de la Russie impériale avec la Chine et du système de déportation et de travail forcé de l'Empire. Il était difficile de s'y forger une identité positive fut-elle corporative (dans le cadre de l'échelle des états, soslovie), nationale ou économique ${ }^{18}$. Sa famille exilée, nombreuse et relativement pauvre, classée par l'administration tsariste comme petite-bourgeoise (meščane) $)^{19}$,

17. Leopold Haimson, The Russian Marxists and the Origins of Bolshevism, $3^{\mathrm{e}}$ éd., Boston : Beacon Press, 1971, p. 209-219. Sur la dichotomie spontanéité versus conscience dans le discours d'identité des bolcheviks, voir également Anna Krylova, « Beyond the SpontaneityConsciousness Paradigm : 'Class Instinct' as a Promising Category of Historical Analysis », Slavic Review, 62 (1), 2003, p. 1-23.

18. A.I. Kremenev, Čitinskaja oblast': Kratkij očerk prirody, ekonomiki i kul'tury [L'oblast de Čita : environnement naturel, économie et culture], Čita, 1955 ; F.A. Brokgauz', I.A. Efron, éds., Enciklopedičeskij slovar' [Dictionnaire encyclopédique], vol. 38, SPb., 1903, p. 880882 ; voir aussi : Daniel R. Brower, The Russian City between Tradition and Modernity, 18501900, Berkeley, CA : University of California Press, 1990 ; Markus Ackeret, In der Welt der Katorga: Die Zwangsarbeitsstrafe für politische Delinquenten im ausgehenden Zarenreich, Munich : Osteuropa-Institut, 2007.

19. Voir le dossier d'investigation de la police tsariste, GARF (Gosudarstvennyj arhiv Rossijskoj Federacii - Archives d'État de la Fédération de Russie), f. 102, op. d.-7, 1904, d. 1278, 1. 7 . 
appartenait aux groupes marginaux de la ville, en dehors de la société établie ${ }^{20}$. Les restrictions d'accès aux institutions d'études supérieures, auxquelles étaient soumis les juifs de l'Empire ${ }^{21}$, forcèrent ce jeune homme ambitieux à se contenter de quatre années de scolarité à l'école élémentaire locale puis d'une formation d'assistant en pharmacie.

Les idées que le futur Jaroslavskij se faisait alors du personnage qu'il voulait être se sont surtout formées dans les cercles de l'intelligentsia russe, constitués à Čita de membres de différents partis antitsaristes exilés en Sibérie ${ }^{22}$, qu'il fréquente en compagnie d'autres étudiants dès son adolescence. Ces cercles, où les mécanismes traditionnels de la division sociale de l'Empire n'étaient pas de mise, étaient caractérisés par une culture profondément livresque dominée dans les années 1890 par deux discours : celui du radicalisme russe de la seconde moitié du XIXe siècle et celui du marxisme. Les représentations révolutionnaires de Jaroslavskij en ont été empreintes, surtout par le premier qui nous semble le plus à même d'expliquer sa construction identitaire. Il était fasciné par le personnage ascétique du martyr révolutionnaire et de l'Homme nouveau, conçu par des auteurs et critiques littéraires comme Nikolaj Černyševskij, Dmitrij Pisarev, Nikolaj Dobroljubov et Vissarion Belinskij. C'est là le modèle, à forte charge émotionnelle, de son propre comportement ${ }^{23}$. Bien que d'orientation résolument athée, la figure du révolutionnaire qui se sacrifie pour le peuple opprimé est façonnée à partir de celle du saint martyr de la tradition orthodoxe russe ${ }^{24}$.

Vers 1895, Jaroslavskij prend enfin connaissance des textes marxistes et, en 1898, adhère au parti social-démocrate. Les membres de ce parti se veulent, avec la théorie du marxisme-léninisme, les seuls à détenir une conception scientifique et rationnelle du monde leur permettant d'analyser leur position dans l'évolution de l'Histoire. Leurs discours opposent discipline, conscience et raison à la spontanéité et à l'émotion. On attendait des membres du parti qu'ils soient des individus conscients, maîtres d'eux et

20. Gregory Freeze, « The Soslovie (Estate) Paradigm and Russian Social History », American Historical Review, 91 (1), 1986, p. 11-36 ; Manfred Hildermeier, « Was war das meščanstvo ? Zur rechtlichen und sozialen Verfassung des unteren städtischen Standes in Russland», Forschungen zur osteuropäischen Geschichte, vol. 36, 1985, p. 15-53.

21. Cf. Guido Hausmann, «Der Numerus clausus für jüdische Studenten im Zarenreich », Jahrbücher für Geschichte Osteuropas, 41 (4), 1993, p. 509-531.

22. Barbara Walker, «Kružkovaja kul’tura i stanovlenie sovetskoj intelligencii : na primere Maksimiliana Vološina i Maksima Gor'kogo » [Les cercles culturels et la constitution de l'intelligentsia : l'exemple de Maksimilian Vološin et de Maksim Gor'kij], Novoe literaturnoe obozrenie, 40 (6), 1999, p. 210-222 ; Id., Maximilian Voloshin's House of the Poet : Intelligentsia Social Organization and Culture in Early 20th Century Russia, Ph.D. dissertation, University of Michigan, 1994.

23. Cf. Susan Morrissey, Heralds of Revolution: Russian Students and the Mythologies of Radicalism, New York : Oxford University Press, 1998 ; Irina Paperno, Chernyshevsky and the Age of Realism: A Study of the Semiotics of Behaviour, Stanford, CA : Stanford University Press, 1988 ; Marina Mogil’ner, Mifologija « podpol'nogo čeloveka » : radikal'nyj mikrokosm $v$ Rossii načala $X X$ veka kak predmet semiotičeskogo analiza [Le mythe de "l'homme du sous-sol »: le microcosme radical en Russie au début du XXe siècle comme objet d'analyse sémiotique], M. : Novoe literaturnoe obozrenie, 1999.

24. Katerina Clark, The Soviet Novel: History as Ritual, $3^{\mathrm{e}}$ éd., Bloomington, IN : Indiana University Press, 2000, p. 52-67. 
disciplinés ; qu'ils ne se laissent surtout pas aller à de fortes émotions ${ }^{25}$. Toute vision du monde considérée comme non scientifique est catégoriquement rejetée. Jaroslavskij lui-même se distingue par un athéisme engagé, ce qui lui vaudra plus tard le poste de direction du mouvement antireligieux en Union soviétique ${ }^{26}$.

Or en dépit de ces convictions théoriques, mythologèmes et impact émotionnel du radicalisme russe ne sont pas évacués par la conversion au marxisme. La réception de ce dernier s'effectue plutôt précisément au prisme du radicalisme russe. L'extrait d'une lettre à sa sœur Etta depuis son exil à Iakoutsk montre à quel point ses idées ont gardé l'empreinte de l'image de l'Homme nouveau :

Et à quel point on m'aime ici ! Parfois c'est même un peu gênant. Gênant, parce que les gens mettent tant d'espoir en moi, que j'ai parfois très peur de les décevoir. Ici habite par exemple une demoiselle qui n'est plus très jeune. [...]. Une enfance très dure a laissé des traces irréparables chez elle, son âme est devenue très solitaire ; son enfance a été sans joie, ainsi que sa jeunesse : la pauvreté, la faim, les orphelinats, la solitude et en plus une neurasthénie héréditaire. Certains pensent qu'elle est un peu dérangée. Elle mène une vie très ascétique et se débrouille avec 15 roubles par mois. Avec ces maigres ressources, elle s'achète des livres et des journaux. Les études représentent la chose la plus importante dans sa vie. C'est sa façon de participer à la vie de sa classe sociale. [...] Elle a développé une attitude tellement favorable à mon égard ; je ne le mérite même pas. Elle m'écrit dans une lettre : souvent, je ne suis pas d'accord avec vous, mais vous avez quelque chose en vous que les autres n'ont pas. Vous avez un côté très doux et j'apprécie beaucoup votre rapport au travail et aux camarades. ${ }^{27}$

La description exaltée de la pitoyable vieille demoiselle contient tous les composants de l'image de l'Homme nouveau. L'évocation de sa relation avec cette femme témoigne de toute l'ardeur de l'intellectuel isolé qui veut se faire aimer du peuple. Jaroslavskij était particulièrement attiré par Insarov, héros du roman Nakanune $[\grave{A}$ la veille] d'Ivan Turgenev. Ce personnage d'un combattant pour la liberté du peuple bulgare a fortement été idéalisé dans un article de Dobroljubov «Kogda nastupaet

25. Haimson, The Russian Marxists and the Origins of Bolshevism, p. 209-210 ; Krylova, «Beyond the Spontaneity-Consciousness... », p. 1-23.

26. Jaroslavskij a initié et dirigé la Ligue des sans-dieu, fondée en 1925, chargée d'organiser la propagande antireligieuse. Entre 1922 et 1929, Jaroslavskij préside la Commission pour la séparation de l'Église et de l'État auprès du CC, responsable de l'administration et de la surveillance des communautés religieuses. Il écrit de nombreux livres, brochures et articles sur des questions religieuses. Quelques-uns de ces ouvrages, dont Biblija dlja verujuščih i neverujuščih [La bible des croyants et des non-croyants], ont été republiés jusqu'aux années 1970. Cf. Arto Luukkanen, The Party of Unbelief: The Religious Policy of the Bolshevik Party, Helsinki : SHS, coll. « Studia historica », 1994 ; Daniel Peris, Storming the Heavens: The Soviet Ligue of the Militant Godless, Ithaca, NY : Cornell University Press, 1998 ; Sandra Dahlke, An der antireligiösen Front: Der Verband der Gottlosen in der Sowjetunion der zwanziger Jahre, Hambourg : Kovac, 1998 ; Ludwig Steindorff, « Zwischen Bürokratie und Ideologie. Die Antireligiöse Kommission beim Zentralkomitee als Koordinator bolschewistischer Religionspolitik in den zwanziger Jahren », Kirchliche Zeitgeschichte, 12 (1), 1999, p. 106-142.

27. Lettre d'Emel'jan Jaroslavskij à Etta Gubel'man, Iakoutsk, 10 novembre 1913. Archives familiales. 
nastojaščij den'» [Quand le jour se lève] ${ }^{28}$. Il est probable que Jaroslavskij s'est identifié à ce point à cette figure littéraire parce que, comme le Bulgare Insarov, il se percevait comme marginal par rapport à la société russe officielle.

Après les événements révolutionnaires de janvier 1905, Jaroslavskij, incarcéré à Odessa, écrit une lettre enthousiaste à ses camarades en liberté à Saint-Pétersbourg. Elle illustre bien l'ardent désir du révolutionnaire intellectuel de se fondre dans le peuple :

Comme la Russie a grandi depuis le 9 janvier ! Elle s'est déjà transformée en une tout autre Russie. Bien sûr, on continue à entendre encore des voix intimidées, à subir la censure castratrice et à sentir l'haleine empestée de ces salauds pourris et dégénérés. Mais le fleuve de la vie pénètre de plus en plus la vie du peuple ; et le marais inerte, à la surface duquel ont flotté des croûtes épaisses de boue et de moisissure pourries, commence à se réanimer. Je vous envie, vous qui êtes à la source de cette vie réanimée et pouvez voir de vos propres yeux comment la conscience du peuple se réveille pour se transformer en vie. [...] Je n'ai jamais éprouvé le sens (soderžatel'nost') de la vie aussi profondément que maintenant. [...] Jamais notre verbe n'a si vivement et si authentiquement été transformé en acte que maintenant. [...] Maintenant il n'y a plus place pour ce pessimisme, pour ce désespoir des jours passés, quand même ceux disposant d'un cœur fort et inlassable ont baissé les bras devant ce «mur» de silence morne, apathique et sans âme [du peuple]. À présent on entend partout des voix joyeuses. Des vagues radieuses ont chassé l'obscurité qui pesait lourd sur notre pays. Allons maintenant attendre l'approche du printemps avec tout notre joyeux espoir, le vrai printemps, qui nous est offert par l'histoire. ${ }^{29}$

Dans cette lettre, dont nous ne disposons que parce qu'elle a été interceptée par la police, Jaroslavskij met tout son espoir dans ce qu'il décrit dans un langage ambitieux, littéraire, teinté de symbolisme : «le réveil du peuple». Le «peuple» (narod) apparaît comme le messie d'un nouvel âge ; le rôle rédempteur de révolutionnaire lui est dévolu. Son soulèvement et sa prise de conscience, que Jaroslavskij croit constater en janvier 1905, sont présentés comme sa propre naissance sociale de révolutionnaire. Cette fusion du mouvement révolutionnaire avec le soulèvement du peuple est considérée comme le moment le plus significatif de sa vie.

Après la prise de pouvoir par les bolcheviks en octobre 1917, son désir de faire corps avec le peuple semble se réaliser essentiellement au contact du grand public. Début 1918, déjà à Moscou, et alors que les bolcheviks se trouvent au sommet de leur popularité, Jaroslavskij écrit à sa femme, Kirsanova :

En ce moment, je suis entouré d'amour. Des milliers d'yeux s'attachent à moi avec tant d'amour quand, deux ou trois fois par jour, j'interviens dans les milieux ouvriers. Et à quel point on m'aime ici ! Hier, à minuit, une vieille femme m'a supplié de venir chez elle pour prendre le thé. Si tu avais vu avec quel amour ils se sont rassemblés autour de moi pendant que je mangeais du saucisson et buvais du thé, et comment ils m'ont dit au revoir! Je te joins une

28. Lettre de Jaroslavskij à Kirsanova, Olekminsk, 17 juin 1916. Archives familiales.

29. RGASPI, f. 89, op. 1, d. 2,1.13-15. 
lettre, une parmi les innombrables que je reçois maintenant. Il y a des hommes et des femmes, âgés ou jeunes, qui s'approchent de moi pour me raconter leurs chagrins et leurs soucis. J'éprouve un sentiment religieux, une espèce d'extase m'envahit, une extase qui se transforme en un sermon sur le socialisme. Et ce sentiment fort se transmet aux autres ! Et ici à Moscou, dans cette ville pieuse, les gens, en retenant leur souffle, m'écoutent, moi l'hérétique, parce que j'oppose l'image douce du Christ, du fils d'un pauvre charpentier, aux métropolites qui revendiquent 300 roubles de salaire..$^{30}$

Notons ici une modification sémantique : en 1905, Jaroslavskij parlait du « peuple », notion propre aux auteurs radicaux; en 1918, il évoque la «masse ouvrière ». Pourtant ni la notion de «peuple» ni la notion marxiste de «masse ouvrière », considérée comme scientifique, ne signifient pour lui une catégorie empirique ou sociologique précise. C'est bien plus une construction intellectuelle, une puissance eschatologique, la promesse de satisfaire les désirs du révolutionnaire. La lettre illustre à quel point Jaroslavskij était pénétré d'un sentiment quasi religieux de faire corps avec cette « masse », de son désir de se faire accepter comme révolutionnaire par ceux au nom desquels il parle, de poursuivre un but commun avec cette « masse », de surmonter l'isolement de l'intellectuel et du juif marginalisé par rapport à la population russe orthodoxe.

Jaroslavskij se présente devant Kirsanova comme un révolutionnaire ardent, altruiste et désintéressé, qui met toutes ses forces au service de la «masse ouvrière ». Mais aussi, ce qui paraît étonnant vu son aversion pour tout ce qui relève du domaine de la religion, du non scientifique, il se compare au Christ comme sauveur du peuple, martyr ascétique de la cause ${ }^{31}$. Pour lui, c'est surtout la souffrance, le sacrifice, mais aussi l'érudition qui rendent radieuse la présence du révolutionnaire, à l'instar de celle du Christ. C'est précisément cette présence radieuse, qu'il nomme krasočnost', sorte de charisme incarné déjà dans la figure de l'Homme nouveau, qui semble le fasciner et qu'il pense transmettre aux « masses ouvrières ». Pour lui, c'est bien à cette krasočnost' que l'on reconnaît un révolutionnaire et, plus important encore, ce qui, l'attachant à la « masse ouvrière », fonde son autorité sur elle. Bien que Jaroslavskij n'ait pas disposé d'une théorie cohérente du processus gouvernemental, il semble évident que, pour lui, ce lien mythique entre le révolutionnaire et « la masse » est au cœur de ce mécanisme.

Dans ses lettres, Jaroslavskij oppose le « révolutionnaire » au « petit-bourgeois ». Dans un article autobiographique de 1927, il décrit cette dichotomie :

30. Lettre de Jaroslavskij à Kirsanova, 2 février 1918. Archives familiales.

31. Le recours à l'image du Christ est un motif récurrent pas seulement chez les auteurs radicaux du XIX ${ }^{\mathrm{e}}$ siècle. Elle resurgit également dans les textes des socialistes et marxistes russes comme chez Maksim Gor'kij et le dirigeant du Narkompros, Anatolij Lunačarskij, associée au bogostroitel'stvo. Le Christ figure dans ces textes comme un objet d'admiration, porteur des valeurs éthiques, personnification d'un dévouement et d'une capacité de souffrance illimitée, le modèle d'une transformation spirituelle de l'humanité ou bien comme prolétaire et meneur des pauvres. Cf. Jay Bergman, « The Image of Jesus in the Russian Revolutionary Movement. The Case of Russian Marxism », International Review of Social History, 35 (2), 1990, p. 220-248. 
Il y a eu quelques camarades qui n'ont pas fait preuve d'ambition pour garder et défendre «l'honneur précieux du rang des révolutionnaires ». Ils se sont noyés dans la masse petite-bourgeoise, en adoptant et en intériorisant les plus mauvaises qualités de cette masse. Quelques-uns parmi les exilés ont même monté leurs petits commerces et ont construit leur maison particulière. Ils n'ont même plus pensé à reprendre le travail de révolutionnaire. ${ }^{32}$

La pire qualité du «petit-bourgeois » est donc son aspiration à des valeurs matérielles, au commerce, à la poursuite de ses propres petits intérêts, à la routine et au confort de la vie quotidienne ${ }^{33}$. Le confort de la vie quotidienne, le monde des objets, est vu comme une tentation permanente qui risque aussi de corrompre le révolutionnaire, son dévouement à la « masse ouvrière » et de le mener à la passivité.

\section{Le quotidien du révolutionnaire et le paradoxe du monde des objets}

Or en 1927, lors de la publication de l'article cité, et surtout dans les années 1930, l'existence de Jaroslavskij et de ses camarades dirigeants bolcheviks n'avait plus rien à voir avec cette image héroïque et ascétique du révolutionnaire. Sa vie dans les années 1930 était marquée par la routine de l'exercice du pouvoir au quotidien, un travail administratif régulier intense, les fins de semaine à la datcha, les soirées au théâtre, au concert, les visites de musées, de longues périodes de repos dans les maisons de santé du parti et enfin... le billard. Il bénéficie d'ailleurs de bien des privilèges typiques des hauts fonctionnaires du parti : une voiture avec chauffeur est à sa disposition ; en 1936 une datcha personnelle lui est attribuée par décision du Bureau politique pour récompenser ses mérites dans le domaine de l'historiographie du parti. Il bénéficie de biens de consommation inaccessibles à la majorité de la population ouvrière. Il habite un grand appartement dans un des immeubles les plus prestigieux réservés à l'élite du parti, l'ancien « bâtiment en grès rouge » construit par les comtes Šeremetev à la fin du XIX siècle rue Granovskij, face à la Bibliothèque nationale. Il a un accès privilégié à des soins médicaux de qualité et aux maisons de repos du bord de la mer Noire. Sa datcha rappelle d'une certaine manière la résidence d'été des familles d'aristocrates russes du XIXe siècle, où étaient logés les protégés et membres moins fortunés de la famille. Elle est fréquentée surtout par des représentants du gotha soviétique : pilotes, écrivains,

32. Emel'jan Jaroslavskij, « Nakanune fevral'skoj revoljucii (1917) » [À la veille de la révolution de Février (1917)], in Emel'jan Jaroslavskij, O Jakutii (stat'i, pis’ma, reči, telegrammy) [De la Iakoutie (articles, lettres, discours, télégrammes)], Iakoutsk, 1968, p. 144-155, ici p. 147.

33. Sur l'anti-image du petit-bourgeois et du philistinisme comme obsession culturelle de l'intelligentsia russe, voir Svetlana Boym, Common Places: Mythologies of Everyday Life in Russia, Cambridge, MA : Harvard University Press, 1994, p. 41-66 ; Timo Vihavainen, The Inner Adversary: The Struggle Against Philistinism as the Moral Mission of the Russian Intelligentsia, Washington, DC : New Academia Publishing, LLC, 2006. 
artistes, metteurs en scène, chanteurs, architectes et scientifiques ${ }^{34}$, à qui Jaroslavskij redistribue les biens matériels et les avantages qui lui ont été accordés par la direction du parti ${ }^{35}$.

Comment Jaroslavskij a-t-il pu accepter ces multiples avantages sans redouter son propre embourgeoisement? Il est étonnant que, malgré ces faveurs, il ne s'estime pas privilégié, mais continue à se considérer comme un combattant de «l'armée des révolutionnaires ». Cette aperception de soi fut facilitée par le fait qu'en Union soviétique un privilégié se définissait moins par ses biens personnels que par son accès aux biens de consommation, dont l'attribution dépendait en dernière instance de la direction stalinienne ${ }^{36}$. Cette façon de gérer les privilèges est telle que les hauts fonctionnaires du parti peuvent penser qu'ils ne possèdent rien et qu'ils n'accordent aucune importance aux biens matériels.

Jaroslavskij et ses camarades appréhendent leurs privilèges à travers un cadre cognitif qui relève du patronage. Jaroslavskij ne perçoit pas les faveurs qui lui sont octroyées comme des privilèges, mais bien comme des marques d'attention du parti réservées à certains de ses membres selon leurs mérites. Les extraits de deux lettres nous éclairent à ce propos. Le premier provient d'une lettre qu'il écrit à sa femme en 1922 ; il travaille alors en Sibérie en tant que secrétaire du Bureau sibérien auprès du $\mathrm{CC}$ :

Il n'y a pas un membre du CC qui puisse avoir idée du travail que je fais ici. Personne n'est aussi proche des masses ouvrières que moi. Maintenant je pars à Moscou et je crains que de nouveau je n'arrive pas à leur dire qu'ils ne peuvent pas continuer à m'exploiter comme ça, que je dois absolument me reposer un peu, ne serait-ce que quelques jours, et si on s'occupe avec tant d'attention de certaines personnes, au point de les envoyer à l'étranger et de les faire soigner par des infirmières, on devrait m'accorder également un minimum de soins. ${ }^{37}$

34. Interview de l'auteur avec Marianna Emel'janovna Jaroslavskaja, 16 juin 2002 ; Marianna Jaroslavskaja : " O moem otce » [Mon père], in P.S. Fateev, V.V. Korolev, éds., O Emel'jane Jaroslavskom: Vospominanija, očerki, stat'i [Emel'jan Jaroslavskij: Souvenirs, études, articles], M. : Izdatelstvo političeskoj literatury, 1988, p. 290-296, ici p. 294-295.

35. Ce mode de comportement était répandu parmi les dirigeants bolcheviks, cf. Sheila Fitzpatrick, «Intelligentsia and Power. Client-Patron Relations in Stalin's Russia », in Manfred Hildermeier, éd., Stalinismus vor dem Zweiten Weltkrieg: Neue Wege der Forschung, Munich : Oldenbourg, 1998, p. 35-53 ; Barbara Walker, Intelligencia Social Organization, op. cit.; voir aussi les contributions au numéro spécial consacré aux réseaux, patronage et clientélisme en Union soviétique : «Patronage, Personal Networks and the Party State », Contemporary European History, 11 (1), 2002.

36. Elena Osokina, Our Daily Bread: Socialist Distribution and the Art of Survival in Stalin's Russia, 1927-1941, Armonk, NY : M.E. Sharpe, 2001, p. 78-81, 94-98 ; Sheila Fitzpatrick, Everyday Stalinism: Ordinary Life in Extraordinary Times, New York : Oxford University Press, 1999, p. 102-106.

37. Lettre de Jaroslavskij à Kirsanova, Novo-Nikolaevsk, 11 mai 1922. Archives familiales. 
En 1943, quelques mois avant sa mort, Jaroslavskij écrit à Stalin :

Cher camarade Stalin! La camarade Kirsanova m'a transmis vos salutations et vos félicitations, et j'ai passé des moments heureux, des moments qu'un homme a rarement le plaisir d'éprouver. Je me suis souvenu que notre père et maître Lenin en 1919, quand il avait été informé que j'avais attrapé le typhus lors d'une mission à Saratov, m'avait envoyé des produits alimentaires très rares à l'époque et une bouteille de champagne. [...] Sa sollicitude ne m'a pas moins soigné que le traitement des médecins. Aujourd'hui, c'est vous qui m'apportez le même réconfort paternel et la même attention de camarade. ${ }^{38}$

Cette lettre à Kirsanova montre surtout que, pour Jaroslavskij, l'attribution de biens matériels signifiait également une augmentation de son propre capital symbolique, illustrant sa position au sein du parti et son intégration dans la hiérarchie d'une oligarchie bolchevique. À ce titre, il est important de souligner ici que cette prétendue proximité des «masses ouvrières » ne pouvant se produire que grâce à son charisme, permet à Jaroslavskij d'argumenter pour revendiquer auprès de la direction du parti reconnaissance et récompense en biens matériels mais surtout en termes de place dans la hiérarchie du pouvoir. Cette économie des faveurs peut paraître paradoxale dans un contexte marxiste, or c'est précisément à travers la distribution des biens matériels par l'institution qui en dispose et qui se définit comme révolutionnaire que l'identité de révolutionnaire de Jaroslavskij et de ses camarades était reconnue ${ }^{39}$. C'était donc essentiellement par le principe du patronage que la qualité de révolutionnaire des dirigeants bolcheviks se trouvait validée et que les dirigeants individuels étaient intégrés dans le groupe des révolutionnaires.

\section{Le quotidien du révolutionnaire et le concept d'aliénation}

Dans la courte introduction biographique, nous avons rappelé que Jaroslavskij commence à tomber en disgrâce à partir de 1931. Son journal et ses lettres à Kirsanova reflètent l'effet qu'eut sur lui cette mise à l'écart du centre du pouvoir. Ces documents révèlent un individu isolé dont la construction identitaire semble irrémédiablement fragilisée. C'est à travers son journal qu'il tente de donner un sens à sa situation, de se rassurer sur son ardeur révolutionnaire. Mais il est incapable de comprendre sa situation, ce que deux notions déjà évoquées permettent d'expliquer: le quotidien et l'aliénation, notions pourtant opposées au champ sémantique du personnage révolutionnaire. Dans la théorie marxiste, la catégorie

38. Lettre de Jaroslavskij à Stalin, 9 juillet 1943. RGASPI, f.558, op. 11, d. 842, 1. 73.

39. Cette économie des faveurs ressemble de façon frappante aux pratiques de pouvoir au XVII ${ }^{\mathrm{e}}$ siècle, cf. p. ex. Mario Biagioli, «Etiquette, Interdependence, and Sociability in Seventeenth-Century Science », Critical Inquiry, 22 (2), 1996, p. 193-238 ; Bruce Mazlish, « Invisible Ties : From Patronage to Networks, Theory, Culture and Society », Explorations in Critical Social Science, 17 (2), 2000, p. 1-20. 
du quotidien est fortement liée à celle d'aliénation. Le quotidien est conçu comme une qualité particulière d'expérience de soi spécifique à un espace social, où une société des consommateurs est dominée par des biens de consommation dont les membres ne participent pas directement à la production. Ce type d'expérience de soi est caractérisé par un sentiment d'individuation, d'isolement par rapport aux autres êtres humains, d'aliénation de soi-même ${ }^{40}$ et, par ailleurs, le sentiment d'une perte des liens avec le passé, d'appartenance à une tradition ${ }^{41}$. L'idée que le phénomène de l'aliénation vient du monde des objets ressemble à la dichotomie, évoquée dans l'article de Jaroslavskij déjà cité, entre le personnage du révolutionnaire, qui agit en tant que sujet tout en représentant les intérêts de la «masse ouvrière », et le petit-bourgeois dominé par les commodités.

La description marxiste des symptômes de l'aliénation liés au quotidien reflète tout à fait l'état d'esprit de Jaroslavskij dans les années 1930. Le régime stalinien avait de son côté engendré une autre aliénation, dont Jaroslavskij et beaucoup de ses camarades subissaient l'effet délétère. Cependant, enfermés dans leur critique du capitalisme, ils ne pouvaient se l'expliquer. Cette expérience de soi éprouvée par Jaroslavskij semble, certes, être liée aux routines du pouvoir, mais aussi, et c'est ce qui nous paraît plus important encore, au régime disciplinaire stalinien, qui évoque plutôt la conception de Hannah Arendt de l'individu isolé et atomisé ou bien la condition d'un détenu dans la prison panoptique de Bentham ${ }^{42}$.

Dans les années 1930, Jaroslavskij éprouve son aliénation par rapport aux trois points de référence à travers lesquels s'était constituée son identité révolutionnaire : la «masse ouvrière », le groupe dirigeant du parti, son attachement aux vieux révolutionnaires.

40. Cf. Henri Lefebvre, Critique de la vie quotidienne, vol. 2 : Fondements d'une sociologie de la quotidienneté, P. : L'Arche, 1961 ; Kristina Kiaer, The Russian Constructivist «Object » and the Revolutionizing of Everyday Life, 1921-1929, Ph. D. diss., University of California, Berkeley, CA, 1995, p. 1-23.

41. Harry Harootunian, History's Disquiet: Modernity, Cultural Practice, and the Question of Everyday Life, New York : Columbia University Press, 2000, p. 1-22. Harootunian conçoit le quotidien en se référant à la notion de l'expérience de Walter Benjamin comme une forme moderne de l'expérience du temps, dans laquelle les liens de la tradition et du passé, radicalement rompus, ne peuvent être reconstitués que dans le cadre de l'expérience du présent.

42. Selon Hannah Arendt, la condition de l'homme dans un État totalitaire est caractérisée par l'expérience fondamentale de l'isolement et de la solitude. Hannah Arendt, Elemente und Ursprünge totaler Herrschaft, Frankfort/M. : Europäische Verl.-Anst., 1955, p. 724-752, ici p. 750. Pour Michel Foucault, qui a repris l'idée de Bentham, la prison panoptique constitue la métaphore la plus pertinente pour décrire les mécanismes de pouvoir des sociétés modernes occidentales. Michel Foucault, Surveiller et punir - la naissance de la prison, P. : Gallimard, 1975. L'application de la théorie foucaldienne au régime stalinien nous paraît pourtant en partie problématique, car ce mécanisme de la surveillance mutuelle, typique selon Foucault des sociétés occidentales, rend justement la violence physique inutile en tant qu'instrument disciplinaire. La terreur stalinienne n'aurait donc pas de fonction particulière. Pour une évaluation critique de la pertinence de la théorie foucaldienne pour la Russie impériale du XIX ${ }^{\mathrm{e}}$ siècle et 1'Union soviétique, cf. Laura Engelstein, « Combined Underdevelopment. Discipline and Law in Imperial and Soviet Russia », American Historical Review, 98 (2), 1993, p. 338-353. Pour une application de la métaphore de la prison panoptique au cas soviétique, cf. Oleg Khakhordin, The Collective and the Individual in Russia: A Study of Practices, Berkeley-Los Angeles-Londres : University of California Press, 1999, p. 114. 
En ce qui concerne le premier point, Jaroslavskij se voyait comme l'acteur d'une avant-garde révolutionnaire qui mène les « masses ouvrières » vers le socialisme. La consolidation du pouvoir bolchevik et la nécessité de gérer la pénurie permanente ont entraîné un sentiment d'aliénation par rapport à ce que Jaroslavskij entendait par la notion de «masse ouvrière ». La tâche de gouverner tout le territoire de l'Union soviétique exigeait d'autres qualités que celles d'un tribun du peuple charismatique, capable par des discours enflammés de mobiliser les «masses » et de se faire acclamer par le public. Dans les terribles années 1932-1933, les « masses ouvrières », épuisées et affamées, n'étaient guère disposées à acclamer un orateur bolchevik. Jaroslavskij était bien au fait des conditions de vie éprouvantes auxquelles était soumise la population après la collectivisation. Lors d'un voyage d'inspection en Sibérie en hiver 1933-1934, il est choqué par la pauvreté omniprésente qu'il compare avec la situation relativement favorable des années 1920, et par l'incapacité du gouvernement soviétique à approvisionner la population. Dans son journal, il exprime de sérieux doutes quant à la capacité du parti à maîtriser la situation, réaliser les promesses de la révolution et apporter un progrès social ${ }^{43}$.

Par ailleurs, par rapport au groupe dirigeant du parti, Jaroslavskij vit sa marginalisation comme une grave crise personnelle, qui remet en question son autoperception même. Il est conscient d'être devenu l'objet du régime disciplinaire stalinien, soumis à une surveillance permanente par ses camarades et ayant dans une large mesure perdu sa capacité d'agir.

Enfin, ce sentiment d'attachement aux vieux révolutionnaires est renforcé par le fait que les vieux bolcheviks et des membres âgés d'autres partis révolutionnaires, regroupés dans deux sociétés de tradition dirigées par Jaroslavskij, disparaissent peu à peu et sont successivement marginalisés par la direction stalinienne ${ }^{44}$.

Dans son journal, Jaroslavskij se sert surtout de catégories physiologiques pour décrire l'effet qu'a sur lui le processus de cette aliénation progressive de ses points de repère. Il parle de son état d'esprit en termes d'épuisement, de fatigue physique, et il semble très préoccupé par la peur de vieillir, de perdre son enthousiasme de révolutionnaire, de ne plus pouvoir suivre... Une lettre à sa fille de janvier 1936 exprime implicitement ses soucis :

43. Journal, 13 et 14 janvier 1934. Archives familiales.

44. La Société des forçats et des exilés politiques du régime tsariste, fondée en 1921, fut dirigée par Jaroslavskij de 1925 jusqu'à sa dissolution en 1935. Cette société regroupait les membres de tous les partis d'orientation socialiste de l'époque prérévolutionnaire. Jaroslavskij a présidé à partir de 1931 la Société des vieux bolcheviks, structurellement associé au Istpart. Fondée en 1922, elle fut dissoute en 1935 à l'initiative de la direction stalinienne. Les deux sociétés s'étaient chargées de la mémorialisation de l'histoire du mouvement révolutionnaire et de l'assistance sociale à ses membres et à leurs familles. Cf. T.P. Koržihina, « Obščestvo staryh bol`̌̌sevikov (1922-1935) » [La société des vieux bolcheviks], Voprosy istorii KPSS, n 11 , 1989, p. 50-65 ; Ja.V. Leontev, M. Junge, « Vsesojuznoe obščestvo politkatoržan i ssyl’noposelencev. Obrazovanie, razvitie, likvidacija, 1921-1935. Byvšie členy obščestva vo vremja Bol'šsogo terrora », in Materialy meždunarodnoj naučnoj konferencii (26-28 oktjabrja 2001 g.) [La société des anciens forçats et exilés politiques de l'Union soviétique. Actes de la conférence internationale (26-28 octobre 2001), M. : Zvenja ; Memorial, 2004. 
Klavdija et moi passons pratiquement toutes les fins de semaines à la datcha. Nous sommes très fatigués par le travail, mais en même temps nous sommes contents de réussir encore à continuer ce grand travail qui est si nécessaire pour notre parti et notre pays. ${ }^{45}$

En novembre 1934, après l'inspection d'un chantier d'une maison de repos gérée par la Société des vieux bolcheviks, Jaroslavskij confie à son journal :

Cette maison, selon toute vraisemblance, va être une des plus belles maisons de repos. Tout a été prévu. Mais on a tout de même un peu mégoté. Devrait-on économiser dans une telle affaire ? Les hommes et les femmes qui appartiennent à cette remarquable cohorte de fer, à la vieille garde des combattants bolcheviks dans la clandestinité, commencent à mourir. Même si, aujourd'hui, beaucoup d'entre eux sont pratiquement inutiles pour la vie, pour le travail, ils ont enduré l'extrême rigueur des années les plus atroces de la révolution. On n'aurait surtout pas dû lésiner pour eux $[\ldots]{ }^{46}$

Une visite de son frère Moisej Gubel'man l'incite à prendre la note suivante :

Nous nous occupons mal des vieux. Aujourd'hui Moisej est venu chez moi. Il a huit ans de moins que moi, mais il a l'air d'en avoir huit de plus. Il vit dans des conditions épouvantables. [...] Pourtant, il a cheminé sans arrêt avec le parti pendant 29 ans, il a enduré les détentions les plus terribles dans les prisons tsaristes, a lutté aux côtés des partisans [...].47

Jaroslavskij refuse de se compter parmi les vieux qui «sont pratiquement inutiles pour la vie, pour le travail ». En tant que membre de la direction stalinienne, il se considère de ceux qui devraient s'occuper davantage des vieux. Et pourtant, sa crainte de bientôt relever, lui aussi, de ce groupe mis à l'écart de la vie politique est nettement perceptible. Ce qu'il déplore ici implicitement, c'est le refus de la direction stalinienne d'assumer son rôle de patron, et de dispenser des ressources aux membres âgés du parti en fonction de leurs mérites et souffrances passées et de leur reconnaître par cet acte de patronage leur identité de révolutionnaire. Lui a-t-il fallu du temps pour comprendre ou bien a-t-il refusé d'accepter que Stalin et ses plus proches collaborateurs aient, autour de 1930, changé les règles du jeu en annulant les lois implicites d'une oligarchie fondée sur le principe du patronage ?

45. Lettre de Jaroslavskij à Marianna E. Jaroslavskaja, 15 janvier 1936. Archives familiales .

46. Journal, 20 novembre 1934. Archives familiales.

47. Journal, 27 novembre 1934. Archives familiales. 


\section{Stratégies disciplinaires et gérontophobie ${ }^{48}$ staliniennes}

À ce titre il est important de porter notre attention sur les stratégies de Stalin destinées à maintenir les autres dirigeants dans un état d'insécurité permanente afin de leur imposer son pouvoir. C'est surtout en instrumentalisant la notion de révolutionnaire et en monopolisant l'histoire de la révolution que Stalin put dominer ses camarades haut placés. Cette notion fut transformée en outil disciplinaire. À notre avis, ces stratégies furent surtout efficaces à l'égard de bolcheviks comme Jaroslavskij, type de l'intellectuel autodidacte sans racines ouvrières, sujet à la crainte permanente d'être isolé et dont la construction identitaire était facile à déstabiliser ${ }^{49}$. Ces bolcheviks étaient particulièrement dépendants de Stalin qui pouvait les accepter dans l'organisme dit révolutionnaire ou bien les en exclure.

Cette stratégie disciplinaire stalinienne peut, par ailleurs, être considérée comme une tentative de résoudre un dilemme fondamental de tout régime révolutionnaire pris entre deux nécessités contradictoires : consolider son pouvoir et ne pouvoir légitimer ce pouvoir que par rapport à la révolution. La préservation de l'esprit révolutionnaire est donc essentielle. Les dirigeants bolcheviks sont ainsi confrontés au même problème du leader charismatique et de son entourage dans la théorie du pouvoir de Max Weber. La qualité charismatique, essentielle pour la légitimité d'un tel régime, ne se conserve qu'à travers des crises qui se produisent, se laissent reproduire ou bien simuler ${ }^{50}$.

Stalin en est bien conscient quand, lors d'une session plénière du CC en 1929, il menace ceux qui, à son avis, ont cédé à la tentation de la droite et plaidé pour une normalisation des relations entre l'État soviétique et les paysans et qui voudraient reculer devant les mesures violentes envisagées par Stalin et ses partisans :

Si nous nous considérions comme de vieux bolcheviks du seul fait de notre âge, alors dans ce cas-là, camarades, notre cause serait en danger. Les vieux bolcheviks ne méritent pas notre reconnaissance uniquement parce qu'ils sont vieux, mais [...] parce qu'ils sont des bolcheviks toujours aux barricades, parce qu'ils sont des bolcheviks qui ne vieillissent jamais. ${ }^{51}$

48. Sur l'obsession gérontophobe récurrente dans les textes de Stalin, voir Mihail Vajskopf, Pisatel' Stalin [Stalin écrivain], M. : Novoe literaturnoe obozrenie, 2001, p. 327-332.

49. Pour une évaluation des bolcheviks-ouvriers et membres de «l'opposition ouvrière », Aleksandr Šliapnikov et Sergej Medvedev, voir les travaux de Barbara Allen : «Aleksander Shliapnikov and the Origins of the 'Workers' Opposition', March 1919-April 1920 », Jahrbücher für Geschichte Osteuropas, 53, 2005, p. 1-24; « Alexander Shliapnikov's Purge from the Soviet Communist Party, 1933-1934», communication, AAASS Annual Convention, Nouvelle-Orléans, 2007 et l'article qui la reproduit, publié dans ce même fascicule, $C M R, 49$ (4), Octobre-décembre 2008, p. 559-580.

50. Max Weber, « Die drei Typen legitimer Herrschaft », in Johannes Winkelmann, éd., Max Weber, Gesammelte Aufsätze zur Wissenschaftslehre, Tübingen : Mohr, 1988, p. 475-488.

51. Iosif V. Stalin, Sočinenija, vol. 12, M., 1949, p. 1-2. 
Cette menace peut entraîner des conséquences sérieuses, comme le démontre quelques années plus tard le cas du vieux bolchevik et membre du Bureau politique Ian Rudzutak. Celui-ci, bien que n'ayant jamais adhéré à un groupe d'opposants à l'intérieur du parti, fut un des premiers, parmi les staliniens loyaux, à être réprimé. Il fut fusillé en 1937. Selon Molotov, Rudzutak a été exécuté non pas parce qu'il était soupçonné d'être déloyal, mais uniquement parce qu'il s'était retiré de la lutte révolutionnaire :

Rudzutak ne s'est pas mal conduit dans les prisons tsaristes. Et à cause de cela, il a pu garder son autorité. Mais à la fin de sa vie - et j'ai eu cette impression déjà à l'époque où il était mon remplaçant - il s'est occupé un peu trop de son propre petit confort. Il n'a plus mené la vraie lutte d'un révolutionnaire. Or à l'époque, cette lutte avait une importance énorme. Il avait tendance à se reposer un peu trop [...] avec ces gens qui, eux aussi, aimaient se distraire. [...] Il s'est adonné à des divertissements petits-bourgeois - il aimait boire et manger en joyeuse compagnie. ${ }^{52}$

Les remarques de Stalin et de Molotov mettent en relief leur redéfinition du révolutionnaire: les vrais révolutionnaires sont ceux qui se montrent prêts à exécuter sans scrupule les ordres de la direction stalinienne et n'ont pas d'autres liens de loyauté. Ils dénoncent donc le système même du patronage et de la méritocratie que Jaroslavskij revendique quand il déplore la situation des vieux bolcheviks. C'est précisément en terrorisant leurs camarades, en les maintenant dans une lutte permanente prétendument révolutionnaire, en supprimant toutes relations autres que verticales que Stalin et son entourage tentent de prévenir le vieillissement du bolchevisme.

Pour Stalin et ses plus proches collaborateurs, il s'agissait non seulement de définir la notion de révolutionnaire et de détruire toutes relations horizontales entre les bolcheviks, mais également leur mémoire de la révolution. En 1935, les deux sociétés présidées par Jaroslavskij, celle des vieux bolcheviks et celle des forçats et des exilés politiques du régime tsariste, sont supprimées à l'initiative de la direction stalinienne. Pour Jaroslavskij, qui s'était fortement opposé à cette mesure, elles constituaient un espace de sociabilité et un lieu de mémorialisation commune des événements révolutionnaires ${ }^{53}$. En 1937-1938, tout en participant à la rédaction du Manuel abrégé de l'Histoire du PCUS(b), Jaroslavskij, en dépit de ses efforts pour sauvegarder la mémoire des révolutionnaires et leurs représentations, en partie malgré lui et en partie dans l'enthousiasme ${ }^{54}$, finit par contribuer à la monopolisa-

52. Feliks Čuev, Sto sorok besed s Molotovym [Cent quarante conversations avec Molotov], M. : Terra, 1991,p. 410-411.

53. Cf. la correspondance entre N.I. Ežov, Stalin, Ja.Ch. Peters et Jaroslavskij et les résolutions portant sur la dissolution de la Société des forçats et exilés politiques du régime tsariste dans le fond personnel de Ežov. RGASPI, f.671, op.1, d.56, publiée dans «Vsesojuznoe obščestvo politkatoržan ... », p. 335-356.

54. Parallèlement à la rédaction de l'Histoire du PCUS(b). Manuel abrégé, Jaroslavskij prépare une histoire du mouvement révolutionnaire du XIXe siècle jusqu'à 1917. Ce projet ne fut jamais achevé. 
tion stalinienne de cette mémoire, monopolisation qui lui vaut sa réintégration, du moins symbolique, à la direction du parti ${ }^{55}$.

La maison de repos, ce lieu où Jaroslavskij et Podvojskij évoquaient la guerre civile en Espagne, où Rudzutak est soupçonné de s'être distrait avec ses amis, le lieu enfin que Jaroslavskij tente de sauvegarder pour ses camarades âgés, représentait, dans l'optique de Stalin et Molotov, le symbole de ces loyautés alternatives illégitimes. Si l'on accorde au quotidien, comme nous l'avons fait, d'être une expérience de soi caractérisée par le sentiment d'isolement par rapport aux autres êtres humains, d'aliénation de soi-même et de perte des liens avec le passé, comment ne pas conclure que le régime disciplinaire stalinien, en détruisant les liens entre personnes et en obérant leur mémoire de la révolution, a visé précisément à générer cette expérience ?

\section{Techniques de motivation}

\section{Le travail acharné}

Pour conserver l'esprit révolutionnaire, pour échapper au destin de Rudzutak et pour éviter à tout prix que le bolchevisme s'épuise et se banalise dans le quotidien, Jaroslavskij et ses camarades ont eu recours à plusieurs techniques de motivation. Le travail acharné fanatique fut, pour les bolcheviks, un moyen de prouver qu'ils étaient toujours sur les barricades. Le martyre du révolutionnaire, qui se sacrifie jusqu'à épuisement à la cause et qui meurt à son poste, était déjà un thème important de cette littérature radicale de la seconde moitié du XIX siècle à travers laquelle s'est constituée l'identité révolutionnaire de Jaroslavskij. Ce thème a été repris dans l'écriture biographique et autobiographique promue par les bolcheviks dès leur prise de pouvoir. Dans ces textes-là, surtout dans les éloges funèbres, les bolcheviks étaient conçus comme des individus à l'énergie inépuisable, dotés d'une volonté de fer indéfectible ${ }^{56}$.

Lors du Premier Plan quinquennal, l'image du révolutionnaire est considérablement modifiée: l'idéal ascétique du révolutionnaire martyr, qui a tant hanté l'imagination de Jaroslavskij, a été remplacé par le modèle du bolchevik viril, de l'administrateur d'industrie extrêmement efficace. Aux côtés de Stalin, ce sont essentiellement Ordžonikidze et Kaganovič qui incarnent cet idéal. C'était également le modèle que Jaroslavskij devait suivre pour ne pas rester à la traîne, pour éviter son exclusion du groupe des « vrais révolutionnaires ». Vu sa situation difficile et la forte concurrence entre dirigeants bolcheviks, son journal lui sert à stimuler sa propre motivation. En novembre 1935, il note :

55. Dahlke, Emel'jan Jaroslavskij, chapitre V, 5.

56. Clark, The Soviet Novel..., p. 49-52, 72. 
Plus de 3000 personnes ont écouté mon intervention : à Kolomna, à Tula, à l'académie communiste, dans le quartier de Frunze. Quel autre propagandiste est capable de travailler autant que moi ? Qui est capable d'une telle production ? Je travaille comme un stakhanoviste. ${ }^{57}$

Après l'assassinat du chef du parti à Leningrad, Jaroslavskij prend les notes suivantes :

J'ai lu dans la Pravda que Kirov a été assassiné par des partisans du groupe de Zinov'ev. À l'époque on m'avait chargé de démanteler ce groupe-là. Quelle lutte n'ai-je pas menée; combien d'ennemis n'ai-je pas arrêtés! Les gens commencent un peu à oublier celui qui a porté sur ses épaules toute cette lutte terriblement dure. Avec la plume, avec le verbe, avec mon travail d'organisation, avec mes articles, pamphlets, ouvrages, discours et mes décisions au sein de la Commission centrale de contrôle, j'ai combattu ces ennemis du parti, et je vais continuer à les détruire aussi longtemps que mes forces le permettront. Et j'ai encore de la force. ${ }^{58}$

Je fais une intervention sur la lutte du parti contre les déviations. Je n'ai pas eu le temps de préparer mon discours. J'ai juste noté au brouillon ce que je voulais dire [...]. Après cela, je suis descendu dans la salle et je ne me suis même pas servi du brouillon. Car j' ai moi-même parcouru tout ce chemin de la lutte du parti contre les déviations. Je me suis activement battu pour la ligne du parti. À cause de cela, les trotskistes m'ont traité de chien de garde de Stalin. Ils ont eu bien raison. Je suis prêt à trancher la gorge de ceux qui osent attaquer Stalin. ${ }^{59}$

Dans son journal, pendant la seconde moitié des années 1930, Jaroslavskij essaye obsessionnellement de se persuader qu'il n'est pas de ces vieux qui se reposent trop, qui sont épuisés et qui ne mènent plus la véritable lutte d'un révolutionnaire.

Pourtant, les stratégies disciplinaires staliniennes ne pouvaient s'accomplir avec autant d'efficacité qu'à la condition d'être relayées par la surveillance réciproque des autres dirigeants. Alors que, de par ses fonctions de dirigeant de l'appareil de contrôle du parti, Jaroslavskij est chargé de vérifier et surveiller ses camarades et se félicite de sa lutte contre les déviations (bor'ba s uklonami), il est bien conscient d'être, lui aussi, épié par des camarades vigilants, et que c'est pour lui une nécessité existentielle de ne pas susciter le moindre doute quant à sa détermination de lutter inlassablement contre l'opposition aux côtés de Stalin :

Je suis tourmenté par des soucis : ne pas avoir participé à la session plénière du $\mathrm{CC}$ était-ce une bonne décision ? Ne devrais-je constater en moi un certain manque d'intérêt par rapport à la vie du parti ? Ou, tout au moins, ne devrais-je pas craindre que quelqu'un puisse interpréter ainsi mon absence pour en tirer profit ? Non, je contrôle chacun de mes pas. Comme il y a vingt, trente ans, le

57. Journal, 24 novembre 1935. Archives familiales.

58. Journal, 20 décembre 1934. Archives familiales.

59. Journal, 5 février 1935. Archives familiales. 
parti représente la chose la plus importante, la plus précieuse, la plus indispensable de ma vie, sans laquelle je suis incapable d'exister. ${ }^{60}$

Il est remarquable que Jaroslavskij exprime sa crainte d'être surveillé par les autres, mais aussi celle que son dévouement à la direction stalinienne puisse être mis en cause. Même s'il décèle les motifs de ses camarades comme bassement dénonciateurs, il commence à transformer cette constatation en doute de soi-même, de son propre dévouement au parti, doute qui se doit d'être aboli.

En décembre 1934, après l'assassinat de Kirov, il écrit à sa femme :

Je me sens très seul ici et à cause de cela j'éprouve des sentiments lourds. Je souffre de mes soucis et de mes angoisses. Je t'ai déjà écrit que Knorin m'avait envoyé un télégramme de la part de la rédaction de Proletarskaja revoljucija, dans lequel il me demande d'écrire un article sur l'opposition zinoviéviste. J'ai accepté, même si ça m'empêche d'effectuer mon travail prioritaire sur la révolution de 1905. Mais je ne peux pas refuser parce que, dans ce cas-là, il se trouverait certainement des camarades pour m'attribuer de faux motifs. Si j'étais à Moscou, je participerais bien évidemment à cette campagne..$^{61}$

Cette lettre révèle un Jaroslavskij moins déterminé à «trancher la gorge » des opposants soupçonnés d'avoir organisé l'assassinat de Kirov. Il semble plutôt angoissé par un sentiment d'abandon et d'isolement d'un être sous surveillance.

\section{L'évocation de la révolution et la création d'un espace virtuel}

Depuis le début de sa carrière, la perception de soi de Jaroslavskij en tant que révolutionnaire est fortement marquée par l'expérience de ses discours devant la foule. Dans ces moments-là, il lui semble surmonter son isolement d'intellectuel, faire corps avec la « masse ouvrière », poursuivre un but commun avec elle et incarner le personnage du révolutionnaire. Dans les années 1930, s’il témoigne de la même ardeur pour « la masse » lorsqu'il relate ses discours, cette ardeur devrait plutôt être considérée comme une espèce de thérapie par laquelle Jaroslavskij essaye d'échapper à la surveillance permanente, de ressusciter des sensations fortes, de se rassurer sur sa construction identitaire de révolutionnaire et d'oublier pour un moment sa situation défavorable. Le 23 octobre 1936, il note dans son journal :

Aujourd'hui, j'ai fait une intervention dans le club «Le marteau et la faucille » devant des cadres du parti du quartier 1 ${ }^{\text {er }}$ Mai. La salle est pleine. Ils suivent mon discours : «Le parti communiste est la troupe de choc de la classe ouvrière » en retenant leur souffle. Ils m'écoutent comme si je racontais un conte merveilleux. Je me laisse passionnément entraîner par eux, je m'enflamme et je vis. Dans les couleurs les plus éclatantes je revis tout le long chemin des quatre dernières

60. Journal, 25 novembre 1934. Archives familiales.

61. Lettre de Jaroslavskij à Kirsanova, 28 décembre 1934. Archives familiales. 
décennies. Je l'ai parcouru avec le parti, j'ai vécu chaque pas que notre parti a fait. Je leur raconte la grandeur magnifique de notre parti, sa lutte et les difficultés qu'il a surmontées. Quand je quitte la salle, des centaines de regards reconnaissants me suivent. Presque personne n'a quitté la salle pendant mon discours de deux heures. Un vieux cheminot m'a dit : "Merci de nous avoir raconté la vraie vie, et d'une façon tellement vraie, comme si moi-même j'avais vécu tout cela. » Je demande à un jeune homme et à une jeune fille : « Est-ce que je ne vous ai pas ennuyés avec mon discours de deux heures ? « Ce serait bien, si on nous ennuyait plus souvent avec des discours comme le vôtre. » ${ }^{62}$

Mais Jaroslavskij ne se contente pas de se remémorer les émotions fortes, de jouer son rôle de révolutionnaire et de se faire aimer et acclamer par son public, il veut également préserver ses impressions. En janvier 1937 il confie à son journal :

Aujourd'hui j'ai fait une intervention à l'École militaire [l'ancienne école du Kremlin]. La salle du manège, que je connais si bien depuis les premières années de la révolution, est pleine à craquer. Je vibre avec des milliers de combattants de l'Armée rouge. J'ai mis dans mon discours toute l'ardeur de mon cœur qui ne cesse de battre, et tout mon savoir sur Lenin et Stalin. Et ils m'écoutent en retenant leur souffle. Je rentre à la maison. Au théâtre Bol'šoj, il y a un concert, mais je veux conserver en moi l'atmosphère de cette soirée. Je préfère donc écouter le concert à la radio. ${ }^{63}$

Même si, dans son journal, Jaroslavskij fait preuve de la même exaltation au contact d'un grand public que dans ses lettres à Kirsanova de la période révolutionnaire, dès les années 1930 la fonction de cette exaltation émotionnelle subit une modification liée au régime disciplinaire que les dirigeants bolcheviks exerçaient l'un sur l'autre. Dans son œuvre majeure Sur le processus de la civilisation, le sociologue Norbert Elias soutient l'hypothèse que le contrôle que les membres d'une entité sociale pratiquent l'un sur l'autre au cours de leurs interactions impose à chacun un contrôle de soi, en particulier de ses pulsions et émotions ${ }^{64}$. Chez les bolcheviks, on observe l'inverse. Pour Jaroslavskij, l'évocation des sentiments forts et de l'enthousiasme est justement une technique pour se discipliner, un travail sur soi, qui doivent le motiver pour la cause, effacer les signes d'épuisement, prouver son inconditionnelle loyauté à Stalin, écarter enfin la tentation de céder à la menace du vieillissement du bolchevisme.

Par ailleurs, il est remarquable que, pour quelqu'un qui se considère comme membre d'une avant-garde révolutionnaire, le passé, c'est-à-dire l'histoire du parti, devienne de plus en plus important. L'évocation rituelle de l'histoire de la révolution devant un public sert à Jaroslavskij de technique pour affronter la banalisation du pouvoir, ne pas perdre les liens avec le passé, se remémorer les événements et les fortes sensations

62. Journal, 23 octobre 1936. Archives familiales.

63. Journal, 22 janvier 1937. Archives familiales.

64. Norbert Elias, Über den Prozess der Zivilisation: Soziogenetische und psychogenetische Untersuchungen, vol. 2 : Wandlungen der Gesellschaft. Entwurf zu einer Theorie der Zivilisation, Frankfort/M. : Suhrkamp, 1997, p. 323-347. 
vécues et, enfin, surmonter son propre sentiment d'isolement. Pendant ces moments-là, il semble de nouveau fusionner avec son modèle du rôle de révolutionnaire.

Il compare son discours à un conte merveilleux. C'est dire qu'il ne s'agit même pas de créer une vraisemblance par rapport aux événements historiques. En revanche, ce qui compte pour Jaroslavskij, c'est la réactualisation permanente de la situation révolutionnaire même, la sensation d'immédiateté que relate son récit. Ce « conte captivant » et sa présence devant un public lui paraissent de toute évidence plus vrais que les événements historiques réels.

Cette ritualisation de l'histoire renvoie à une autre technique développée et appliquée par des contemporains pour éviter la banalisation du projet révolutionnaire, dissiper leurs craintes que la révolution n'ait pas tenu ses promesses, transformer enfin leurs doutes en enthousiasme. Cette technique est le réalisme socialiste. Ce n'était pas seulement une doctrine littéraire, une méthode artistique, une forme d'art, un programme esthétique ou bien une variante kitsch avec laquelle les dirigeants bolcheviks tentaient de tromper les membres du parti et les ouvriers tout en occultant leurs propres excès, c'était aussi un mode de perception ${ }^{65}$. Pour Jaroslavskij, ce mode de perception est un remède qui lui permet de soigner le malaise suscité par son sentiment d'isolement.

Les extraits suivants du journal font penser à une description d'un tableau typique de l'époque stalinienne ${ }^{66}$. Ils dévoilent la façon dont Jaroslavskij s'est intégré dans l'espace sacré au-delà du quotidien du réalisme socialiste. La première note fut prise lors de l'ouverture du XVIIe Congrès du parti en janvier 1934, la seconde en novembre 1936 lors de l'inauguration du VIII' Congrès extraordinaire des Soviets. Les deux événements ont eu lieu dans la grande salle du Grand palais du Kremlin, récemment rénovée ${ }^{67}$ :

Cet après-midi : ouverture du Congrès. Quelle salle magnifique a émergé de ces deux voûtes ! Je suis à la tribune, la salle est envahie par les gens. Au-dessus des têtes, des lustres brillants diffusent la lumière dans toute la salle. ${ }^{68}$

Aujourd'hui, le VIII ${ }^{e}$ Congrès des Soviets a été inauguré. Lors du début glorieux de l'Internationale, une nouvelle page de l'histoire de notre magnifique pays socialiste s'ouvre. Les mots me manquent pour exprimer les émotions qui me bouleversent, quand la masse des peuples soviétiques acclame la Constitution et les conquêtes du socialisme. La conscience profonde d'avoir lutté moi-même pour cette victoire remplit tout mon être de joie et de fierté. Je dirige mon regard

65. Cf. Fitzpatrick, Everyday Stalinism..., p. 9 ; Clark, The Soviet Novel..., p. 91 ; Evgeny Dobrenko, «Socialism as Will and Representation, or what Legacy are we Rejecting », Kritika, 5, 2004, p. 675-708.

66. Voir par exemple la reproduction $n^{\circ} 169$, « An unforgettable meeting, 1936/37 », de Vasilij P. Efanov (Galerie Tretjakov, Moscou) et la reproduction n ${ }^{\circ} 171$, « Leader, teacher and friend (Comrade Stalin at the Congress of collective farm shockworkers) ", de Grigori M. Shegal (1937, collection privée), in Matthew Cullerne Bown, Socialist Realist Painting, New Haven, CT : Yale University Press, 1998, p. 163-164.

67. Pravda, 27 janvier 1934, p. 1.

68. Journal, 26 janvier 1934. Archives familiales. 
vers Stalin. Il est à deux pas de moi. Avec lui j'ai parcouru tout ce chemin et je le connais depuis 1905. Là, il attend calmement que les applaudissements faiblissent pour commencer son discours, un discours simple, serein et sans prétention, qui, comme un monument magnifique, va entrer dans l'histoire de l'humanité tout entière. Aujourd'hui est un des jours les plus heureux de ma vie. ${ }^{69}$

C'est bien en s'intégrant dans le cadre du réalisme socialiste que Jaroslavskij réussit à surmonter son isolement, à échapper à la surveillance mutuelle (à laquelle lui-même participe), à faire corps avec « les masses » des peuples de l'Union soviétique et avec Stalin dans l'histoire du parti. Dans ce cadre esthétique, les promesses de la révolution semblent s'être réalisées. Nos trois points de repère - masse ouvrière, direction du parti et vieux bolcheviks - , que Jaroslavskij avait éprouvés en termes d'aliénation, convergent dans un tableau où la frontière entre espace réel et espace imaginaire devient de plus en plus floue. C'est en s'imaginant dans cet univers virtuel que Jaroslavskij parvient, ne serait-ce que quelques instants, à échapper à la terreur du quotidien.

Certes le régime disciplinaire stalinien mettait Jaroslavskij et ses camarades mal à l'aise. Ils se trouvaient dans une situation paradoxale : Stalin, et lui seul, par sa gestion de la notion de révolutionnaire rendait illégitime tout autre point de repère qui aurait permis à ses camarades dirigeants de se rassurer sur leur identité de révolutionnaire, lui seul pouvait les intégrer dans une institution qui se définissait comme révolutionnaire et confirmer par là l'idée qu'ils se faisaient d'eux-mêmes. Ainsi toute opposition par rapport à la figure de Stalin et toute évaluation critique de ses stratégies disciplinaires n'étaient devenues possibles qu'au prix d'une rupture avec l'institution même, d'une destruction de la notion de soi en tant que révolutionnaire. C'est ainsi que Jaroslavskij, figé dans le temps révolutionnaire et dans l'espace virtuel du réalisme socialiste, s'inscrit désormais dans un espace où toute capacité de jugement est dérisoire.

Helmut-Schmidt-Universität/Universität der Bundeswehr, Hamburg

dahlke@hsu-hh.de

69. Journal, 25 novembre 1936. Archives familiales. 